\title{
Copro-prevalence and risk factor assessment of gastrointestinal parasitism in Indian domestic pigs
}

\author{
D. SHARMA ${ }^{1, *}$, N. K. SINGH ${ }^{2}$, H. SINGH², S. S. RATH ${ }^{2}$ \\ 1Department of Veterinary Parasitology, DGCN College of Veterinary \& Animal Sciences, CSKHPKV, Palampur-176062, India, \\ *E-mail: devinasharma23@yahoo.co.in; ²Department of Veterinary Parasitology, College of Veterinary Science, \\ Guru Angad Dev Veterinary and Animal Sciences University, Ludhiana - 141004, India, \\ E-mail: nirbhayksingh@yahoo.co.in, drharkiratsingh@hotmail.com, drssrath59@gmail.com
}

Article info

Received February 2, 2019

Accepted December 23, 2019

\section{Summary}

The aim of the present study was to determine copro-prevalence of gastrointestinal parasites and their associated potential risk factors in pigs of Punjab (India). A total of 839 faecal samples were collected from pigs of all age group and sex from different agro-climatic zones of Punjab covering all seasons and subjected to qualitative and quantitative examination. Among the samples examined, $28.4 \%$ were positive for gastrointestinal parasites and their respective prevalences were Ascaris suum $(11.1 \%)$, coccidia (9.41\%), Trichuris suis (6.43\%), Balantidium coli (4.5\%), amphistome (3.33 \%), strongyle (2.14 \%) and Ascarops strongylina (1.78\%). Upon sporulation of coccidian positive samples, 8 species of Eimeria were recorded (Eimeria polita, E. spinosa, E. scabra, E. perminuta, E. suis, E. debliecki, E. neodebliecki and E. porci). Among the various risk factors analysed, season, agro-climatic zones and managemental practices had a significant $(p<0.05)$ effect on gastrointestinal parasitism of pigs. Quantification of the infection levels in various seasons and age groups revealed the highest mean egg per gram in rainy season (1966. $6 \pm 1146.5)$ and grower pigs (1457.1 \pm 500.4 ). Coproculture analysis revealed the presence of larvae of Hyostrongylus rubidus and Oesophagostomum species. The results of the current study would be of immense help in formulation and implementation of control strategies for effective control of gastrointestinal parasitism in pigs.

Keywords: coprology; India; prevalence; gastrointestinal parasites; pig; risk factors

\section{Introduction}

Internal parasites are the major biological constraints to efficient pig production but they are often overlooked as the clinical symptoms are rarely apparent. In pigs, parasites cause $5 \%$ and $31 \%$, reduction of the daily feed intake and average daily growth, respectively and an average $17 \%$ higher Feed Conversion Ratio compared to the parasite-free fattening pigs (Ózsvári, 2018). In India, majority of pigs are raised under free range system where they feed upon raw garbage, kitchen waste and faecal matter, making them more prone to parasitic infections (Tiwari et al., 2009). Moreover, the close association between pigs and humans enables cross-infection with a range of zoonotic parasites like Taenia solium, Trichinella spiralis and Toxoplasma gondii, all of which contribute deleteriously to human health. Pigs are infected with wide range of gastrointestinal $(\mathrm{GI})$ parasites with reports from all corners of the world (Permin et al., 1999; Tamboura et al.2006; Lai et al., 2011; Navarro-Gonzalez et al., 2013; Yui et al., 2014;Alynne et al., 2015; Junhui et al., 2015; Kabululu et al., 2015; ) including India (Laha et al., 2014; Dadas et al., 2016; Joute et al., 2016;

\footnotetext{
* - corresponding author
} 
Krishna Murthy et al., 2016; Singh et al., 2017; Patra et al., 2019). Age, sex of animal, management practices and geographical location are the major risk factors associated with $\mathrm{Gl}$ parasites in pigs (Permin et al., 1999; Geresu et al., 2015; Roesel et al., 2017). It is predicted that in next ten years, the total consumption of meat in India will double from its present numbers and hence more emphasis need to be given for the efficient and economical pig husbandry. The growing demand for pork due to the growth of hotel industry and proliferation of fast food chains in the country has prompted farmers in Punjab to go in for pig farming in a big way. In preview of the significance of $\mathrm{Gl}$ parasites as one of the most important causes of economic losses to pig industry (Roesel et al., 2017) and lack of data from Indian states, it was justified to reassess the prevalence and its associated risk factors from Punjab state.

\section{Materials and Methods}

\section{Sampling procedure}

As per the $19^{\text {th }}$ Livestock Census (2012) of India, population of the pigs in Punjabis approximately 32,221 (DAHP, 2016). . The sample size for each category according to demography and management was calculated by employing software EpiTool (http://epitools.ausvet.com.au). The state population of 32221 heads with an expected prevalence of $50 \%$ for GI parasites, margin of error as $3.1 \%$ $(\leq 5 \%)$, and a $95 \%$ confidence interval $(\mathrm{Cl})$ resulted in sample size of approximately 320 . However, additional convenient sampling was done to include more samples in the study. Thereafter, cluster sampling was employed where each of five agro-climatic zones namely sub-mountain undulating zone (I), undulating plain zone (II), central plain zone (III), western plain zone (IV) and western zone (V) formed a single cluster each and a systematic sampling comprising of villages representing each cluster was done. As the pig population was unevenly distributed, sampling from the villages which were representative of each cluster was done. Thus, total of 839 faecal samples of pigs from 18 districts comprising 32 villages representing 5 agro-climatic zones were collected. A total of 36 commercial and backyard farms were sampled throughout the year covering all the seasons viz. summer (March to June), rainy (July to October) and winter (November - February) and a proportional sampling scheme was adopted. Faecal samples were collected from the suckling and weaner piglets ( $<4$ months), growers (4-8months) and adults (>8months) from both the sexes.

\section{Data collection}

Information regarding various risk factors hypothesized to be associated with the prevalence of $\mathrm{Gl}$ infection i.e. type of farm management (organised/ unorganised), water consumption (controlled/ uncontrolled), deworming (present/absent) and cleanliness status of the farm (present/absent) based on the scores like regular removal of waste material from sheds and drainage etc. was collected through predesigned questionnaire.
Sample processing and examination

The faecal samples were collected immediately after defecation, and subjected to qualitative faecal examination techniques (concentration-flotation and sedimentation technique) as per standard protocols (Soulsby, 1982). Quantification of strongyle infection was done by McMaster technique (MAFF,1986). Faecal cultures were prepared by incubating $5-10 \mathrm{~g}$ of faeces at $26-28^{\circ} \mathrm{C}$ for $5-$ 7 days after which infective larvae were isolated using a modified Baermann technique as described by Roberts \& O'Sullivan (1950).

\section{Data handling and statistical analysis}

The analyses were conducted using IBM SPSS Statistics for Windows, Version 22.0 statistical software (released 2013. (c) 2013, Armonk, NY: IBM Corp). The bivariate association between each hypothesized risk factor and GI parasitic infection in pigs was evaluated using the Pearson chi-square test for categorical and continuous variables. The factors significantly associated with the risk of infection with $\mathrm{Gl}$ parasites were then subjected to regression analysis. A binary logistic regression analysis model was developed and the relationship between the prevalence of infections and independent variables was analysed using coprological status (positive/negative) as dependent variable. The effect of each risk factor on the likelihood of infection was measured by the odds ratio (OR) along with their $95 \% \mathrm{Cl}$ was computed as the exponent of the respective regression coefficient. Cluster analysis was performed to identify parasites that were more likely to cluster or coexist, by applying an unsupervised hierarchical cluster analysis algorithm, available in Pvclust package (Suzuki \& Shimodaira 2006) in R statistical software ( $R$ Core Team, 2005). A binary method of similarity was used between the dichotomous variables for each of the parasites and the unweighted pair group method with arithmetic mean (UPGMA), as the dissimilarity measure between clusters. This analysis was run for 1,000 iterations using bootstrap resampling techniques which provided with approximately unbiased probability values (AU $P$-value) for clusters; clusters with AU $P$ value of $>95 \%$ indicated significant clusters.

\section{Ethical Approval and/or Informed Consent}

This study was reviewed and approved by the Dean of Post Graduate studies, Guru Angad Dev Veterinary and Animal Science University (GADVASU), Ludhiana, Punjab, India. More detailed ethical review was not required since no invasive sampling was undertaken.

\section{Results}

Prevalence of $\mathrm{Gl}$ parasites in pigs

Out of the 839 pig faecal samples analysed, 238 (28.4\%) were found positive for one or more GI parasites. Ascaris suum was the predominant species with a prevalence of $11.1 \%$. The other GI parasites recorded were coccidia $(9.41 \%)$, Trichuris suis $(6.43 \%)$, 

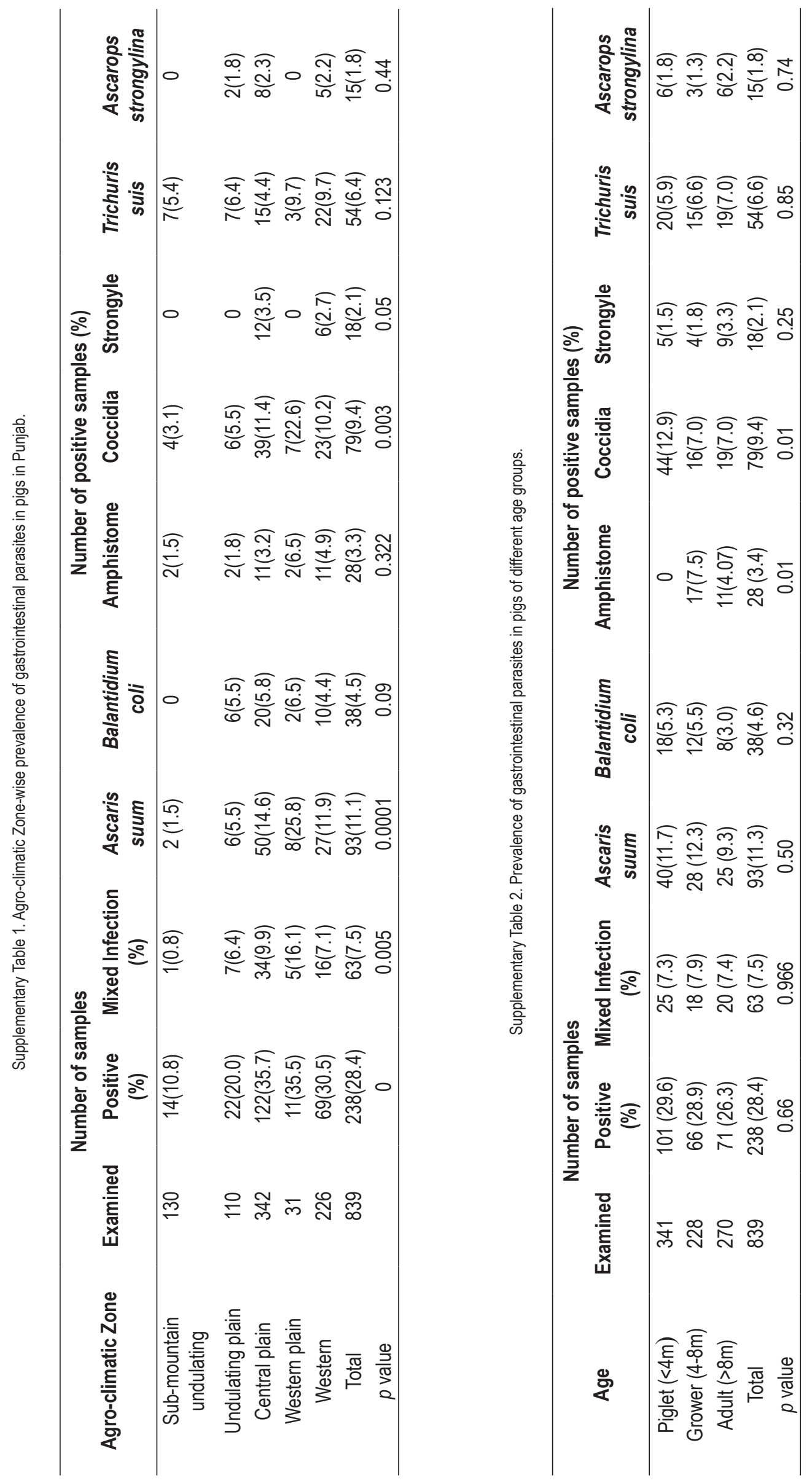

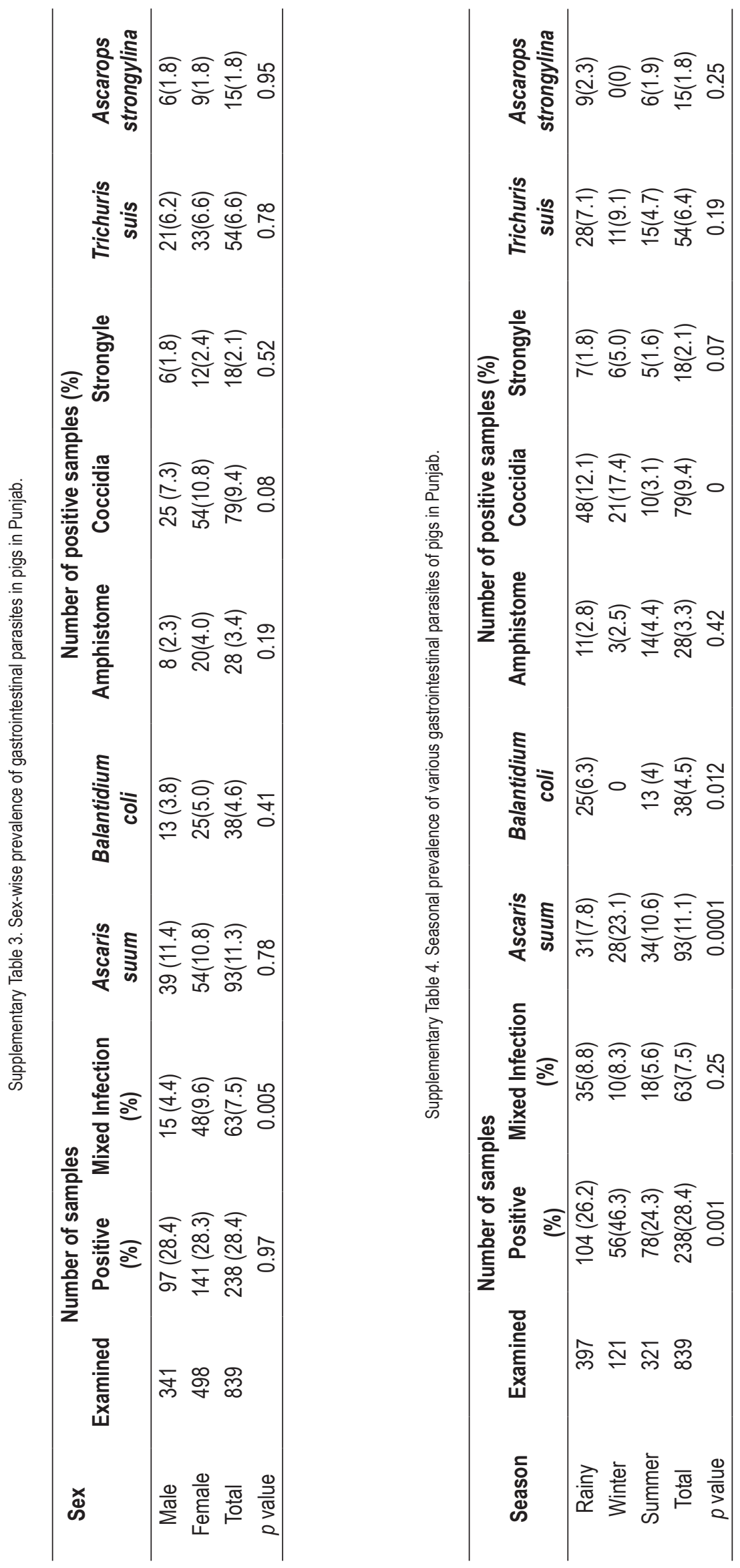


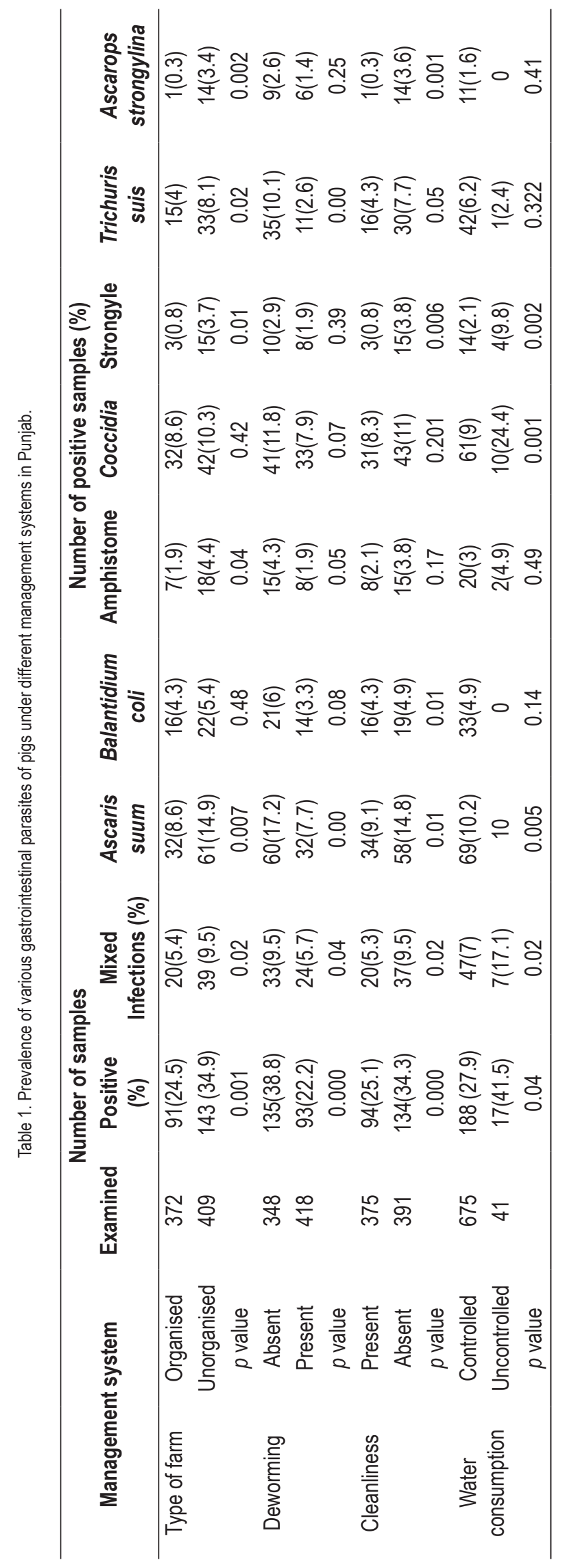


Balantidium coli (4.5\%), amphistome (3.33\%), strongyle (2.14\%) and Ascarops strongylina (1.78\%). The morphometric studies of the coccidian oocysts revealed eight species of Eimeria in pigs of Punjab, India viz. Eimeria polita, E. scabra, E. porci, E. debliecki, E. spinosa, E. suis, E. neodebliecki and E. perminuta. Faecal cultures followed by modified Baermann technique revealed presence of larvae of Hyostrongylus rubidus and Oesophagostomum species.

\section{Zone wise prevalence of $\mathrm{Gl}$ parasites}

Among different agro-climatic zones of Punjab, a significant difference $(P<0.05)$ in prevalence of $\mathrm{Gl}$ parasites was observed. Central plain zone $(\mathrm{OR}=2.24 ; \mathrm{Cl} 95 \%: 1.41-3.557)$ and undulating plain zone (OR=1.11, Cl $95 \%: 0.606$ - 2.05) had the increased odds of GI parasitic infection as compared to western zone (reference zone) (Supplementary Table1).

\section{Age wise and sex wise prevalence of GI parasites}

The age of host had a non-significant $(P>0.05)$ effect on prevalence rates (Supplementary Table 2). The higher proportion of pigs $(81.25 \%)$ had moderate (500 - 2000 EPG) infection with strongyles. Further, the highest intensity of infection was recorded in growers (1457.1 \pm 500.4$)$ followed by piglets $(900.2 \pm 161.2)$ and adults (466.6 \pm 176.3$)$. Further, statistically non-significant $(P>0.05)$ difference and almost similar prevalence of $\mathrm{GI}$ parasites was recorded in males $(28.4 \%)$ and female $(28.3 \%)$ pigs (Supplementary Table 3).

\section{Seasonal prevalence of $\mathrm{Gl}$ parasites}

A significant $(P<0.05)$ seasonal variation was recorded with the highest prevalence in winter season $(46.3 \%)$ followed by rainy $(26.2 \%)$ and lowest in the summer (24.3\%) (Supplementary Table 4). The results indicated that pigs had more odds of acquiring the infection during winter (OR 4.36; $\mathrm{Cl} 95 \%$ : 1.58 - 9.51) and rainy (OR: 1.16; CI $95 \%$ : 1.11 - 2.34) season. Further, quantification of the infection levels by McMaster technique revealed the highest mean EPG in rainy season (1966.6 \pm 1146.5$)$ followed by summer (1876.6 \pm 1124.4$)$ and winter (560.6 \pm 146.9$)$.

\section{Risk factor assessment}

The results revealed that the uncontrolled water consumption from unidentified water sources such as streams and drains $(\mathrm{OR}=3.88$ [1.58 - 9.51]), unorganised farms ( $O R=5.201$ [1.69 - 15.92]) and absence of deworming (OR=1.16 [1.11 - 2.34]) significantly increased the odds of infection with $\mathrm{Gl}$ parasites in pigs (Table 1,). The location (OR=3.27 ([0.51 - 4.49]) and absence of deworming $(\mathrm{OR}=2.24[1.41-3.59])$ increased odds of infection with $A$. suum. The absence of deworming (OR= 2.604 [1.28 - 5.27]) was significantly associated with the infection with $B$. coli whereas, season, deworming and uncontrolled water consumption increased the odds for infection with Trichuris suis.

\section{Discussion}

Prevalence rates in range of $11-38 \%$ have been reported in pigsfrom various geographical locations in India (Kumari et al., 2002; Deka et al., 2005; Borthakur et al., 2007; Godara \& Sharma 2010; Singh et al., 2017). Kaur et al.,2017 have recorded an overall higher prevalence of $56.5 \%$ in pigs of more than 1year age from Punjab, India. This might be due to the differences in the sampling criteria as they targeted scavenging pigs and had included only a few pigs from organised farms. Similarly, infection of pigs with $\mathrm{GI}$ parasites with prevalence rates varying between 13.2 to $96.4 \%$ has been widely reported from all corners of world (Roepstorff \& Jorsal 1989; Roepstorff et al., 1998;; Tamboura et al ., 2006; Tiwari et al., 2009; Ismail et al., 2010; Lai et al., 2011; Obonyo et al., 2013; Dey et al., 2014; Okorafor et al., 2014; Alynne et al., 2015; Lipendele et al.,2015; Atawalna et al., 2015; Nonga \& Paulo, 2015; Junhui et al., 2015; Roesel et al., 2017; Chilundo et al., 2017; Kouam et al., 2018) . The parasite spectrum was similar to that of previous studies from other tropical or subtropical countries (Tamboura et al., 2006; Nissen et al., 2011; Chilundo et al., 2017). Within Punjab state, India, Central plain zone and undulating plain zone have more humid conditions as compared to other zones, thus facilitating survival, development and propagation of the pre-parasitic stages of the GI parasites, hence higher prevalence rates.

Ascaris suum (11.1\%) was recorded as the predominant GI parasite of pigs which is in agreement with the findings of Yadav \&Tandon (1989from sub-tropical regions of India. The prevalence rate of Trichuris suis $(6.43 \%)$ was low and was similar to the reports from other tropical countries like Ghana (4.6\%) and Zimbabwe (4.2\%), by Permin et al., (1999) and Marufu et al., (2008), respectively. Ismail et al. (2010) from Korea, Giarratana et al. (2012) from Italy and Dey et al. (2014) from Bangladesh reported higher prevalence rate of $B$. coli as $64.7 \%, 36.66 \%$ and $40 \%$, respectively which is contrary to the findings of the current study (4.5\%).

Variation in prevalence of various species of GI parasites observed in the current study and other regions of the world, suggested that geographical location along with management practices including hygiene and deworming are the major determinants responsible. Nonetheless, not only the macroclimate, but the microclimate of the pens i.e. flooring and drainage facilities provide optimum conditions including moisture and temperature for the propagation and existence of pre-parasitic stages in the contaminated feed and surroundings. In addition to these, differences in the basic biological requirements of the pre-infective developmental stages, transmission characteristics and immunogenicity of the different worm species are the contributors. Availability of clean water, practice of open defecation with easy access of pigs, housing, inadequate feed to the pigs, health status as well as inherent characteristics such as host immunity are the other important determinants.

The result of present study suggested that sex of the pigs did not have direct bearing on the prevalence of GI parasites. Similar ob- 
servations has been reported by other researchers (Yadav \&Tandon, 1989; Tamboura et al., 2006; Kumsa \& Kifle, 2014; Okarafor, 2014). The highest intensity of infection with strongyles (EPG) was recorded in growers followed by piglets and adults. This can be ascribed to the fact that growers get exposed to the infective stages while they forage on grasses after weaning. The infection rates in piglets are associated to their immune status, level of pre-exposure and nutritional status while adults develop resistance against re-infections.

A significant $(P<0.05)$ seasonal variation was recorded with highest intensity of infection during rainy season followed by winter with large proportion of animals having moderate infection. This finding can be attributed to the fact that suitable environmental conditions like temperature and humidity during this period for development of preparasitic stages makes maximum availability of infective stages to the host. The infection in the winter season may be ascribed to the reduced immuno-tolerance of animals and long prepatent periods of some of the GI parasites. Similar seasonal variations have been reported by Muraleedharan (2005) and Kagira et al.(2010).

It was found that the factors like unorganised farms, absence of deworming and pigs consuming water from unknown sources significantly increased the odds of infection with GI parasites. This could be credited to the habit of coprophagy and scavenging by the pigs which make them more prone to parasitic infections as pigs reared under unhygienic conditions have free access to garbage and contaminated feed and water. Analogous were the findings of Kagira et al. (2010) who have considered confinement or housing as a protective factor against GI parasitism in Western Kenya. There was less evidence of $\mathrm{GI}$ parasites in pigs with effective deworming programmes and better farm hygiene. Similar were the findings of a survey conducted in Nigeria by Weka \& Ikeh (2009) who found a negative correlation between the prevalence of intestinal parasites and routine deworming of the pigs. However, this is in contrast to the findings of Roesel et al. (2017) who have reported that administering anthelminthic drugs have no significant impact on the prevalence of GI parasites in pigs.

Cluster analysis of the parasites did not identify any significant clusters in the present data. The three parasitic infections (B. coli, $T$. suis and mixed infection) were closer to each other as compared to other parasites. There have been earlier reports of chronic diarrhoea associated with Balantidium and Trichuris concurrent infection in canines (Ewing \& Bull 1966). However, the importance of this co-occurrence in pigs which although was non-significant, needs to be explored further, especially in diarrhoeic animals.

Thus, our findings revealed that the pigs get infected by wide array of $\mathrm{GI}$ parasites. Due to their behaviour of coprophagy, pigs are likely to ingest infective stages from the environment. The unorganised farm management system, water consumption from unknown sources and lack of deworming schedule makes them more prone to the risk of $\mathrm{GI}$ parasitism.

\section{Conclusion}

Gastrointestinal parasites are prevalent in pigs of Punjab state, India with a prevalence rate of $28.4 \%$ and Ascaris suum as the predominant parasite. Among the various risk factors analysed season, agro-climatic zones and managemental practices had a significant $(p<0.05)$ effect on $\mathrm{GI}$ parasitism of pigs. Therefore, managemental practices viz. routine removal of manure and litter from pig pens, anthelmintic treatment during rainy and summer season and the use of disinfectants in the pens can be helpful in effective control of $\mathrm{Gl}$ parasites of pigs.

\section{Conflict of Interest}

Authors state no conflict of interest.

\section{Acknowledgments}

The authors acknowledge The Dean, Post Graduate Studies, Guru Angad Dev Veterinary and Animal Science University, Ludhiana, Punjab, India for providing facilities to carry out the research work. Thanks are also due to the farmers who generously gave their time and hospitality.

\section{References}

Akinkuoto, O.A., Jacobs, E.B., Egbetadea, O. (2015): Prevalence of strongylids of pigs in Ogun state, southwest Nigeria. Niger. J. Anim. Prod., 42: 223 - 227

Alynne, S.B., Otilio, M.P.B., Laís, V.D., Mayarap, De, S., Matheus, L.C., LuIz, Claudio, F. (2015): Gastrointestinal parasites of swine raised in different management systems in the State of Rio de Janeiro, Brazil. Pesqui Vet Bras, 35: 941. DOI: 10.1590/S0100736X2015001200001

Atawalna, J., Атtoh-Kotoku, V., Folitse, R.D., Amenakpor, C., AtaWALNA J. (2015): Prevalence of gastrointestinal parasites among pigs in the Ejisu municipality of Ghana. Sch J Agric Vet Sci, 3: $33-36$

Borthakur, S.K., Rahmani, S., Sarma, K., (2007): Prevalence of gastrointestinal helminths in pigs in Aizwal. J.Vet. Parasitol., 21: 173 - 74. DOI: 10.9790/2380-07433138

Cameron, A.R. (1999): Survey toolbox for livestock diseases: a practical manual and software package for active surveillance in developing countries. Monograph no. 54. Australian Centre for International Agricultural Research, Canberra, 330 pp. Retrieved from http://epitools.ausvet.com.au/docs/SurveyToolbox.pdf.

Chilundo, A.G., Mukaratirwa, S., Pondja, A., Afonso S, Miambo R., Johansen, M.V. (2017): Prevalence and risk factors of endo- and ectoparasitic infections in smallholder pigs in Angónia district, Mozambique. Vet Parasitol Reg Stud Reports,7: 1 - 8. DOI: $10.1007 /$ s11250-017-1474-6

DAHP - Department of Animal Husbandry Punjab (2016): Servi- 
ces - livestock census. Retrieved from http://www.husbandrypunjab.org.

Dadas, S., Mishra, S., JawalagattI, V., Gupta, S., Vinay, T.S., GudeWAR, J. (2016): Prevalence of gastrointestinal parasites in pigs (Sus scrofa) of Mumbai region. Int. J. Sci. Env. Tech., 5: 822 - 826 Deka, D.K., Borthakur, S.K., Patra, G. (2005): Parasitosis in domestic animals and birds of Aizawl, Mizoram. J. Vet. Parasitol., 19: $51-53$

Dey, T.R., Dey, A.R., Begum, N., Akther, S., Barmon, B.C. (2014): Prevalence of end parasites of pig at Mymensingh, Bangladesh. J. Agri. Vet. Sci., 7: $31-38$

EwING, S.A., BuLL, R.W. (1966): Severe chronic canine diarrhea associated with Balantidium-Trichuris infection. J. Am. Vet. Med. Assoc., 149: 519 - 520

Geresu, M.A., Hallemariam, Z., Mamo, G., Tafa, M., Megersa M. (2015): Prevalence and associated risk factors of major gastrointestinal parasites of pig slaughtered at Addis Ababa Abattoirs Enterprise, Ethiopia. J Vet Sci Technol, 6: 4 - 11

Giarratana, F., Muscolino, D., Taviano, G., Zilno, G. (2012):Balantidium coli in pigs regularly slaughtered at abattoirs of the province of Messina: Hygienic observations. Open J. Vet. Med., 2: 77 - 80. DOI: 10.4236/ojvm.2012.22013 5,408

Godara, R., Sharma, R.L. (2010): Parasitic infections in livestock at Jaipur. J. Vet. Parasitol., 24: 193 - 195

Hale, O.M., Stewart, T.B., Marti, O.G. (1985): Influence of an experimental infection of Ascaris suum on performance of pigs. $J$. Anim. Sci., 60: 220 - 225

Haque, M., JyotI, Singh, N.K., JuYal, P.D., Singh, H., Singh, R., Rath, S.S. (2011): Incidence of gastrointestinal parasites in dairy animals of western plains of Punjab. J. Vet. Parasitol, 25: $168-170$ IsmAlL, H.A.H.A., JeON, H.K., Yu, Y.M., Do, C., LeE, Y.H. (2010): Intestinal parasite infections in pigs and beef cattle in rural areas of Chungcheongnam-do, Korea. Korean J. Parasitol., 48: 347 - 49. DOI: $10.3347 / \mathrm{kjp} .2010 .48 .4 .347$

JoUTE, J.R., GILL, J.P.S., SINGH, B.B. (2016): Prevalence and molecular epidemiology of Cryptosporidium parvum in dairy calves in Punjab (India). J. Parasit. Dis., 40: 745 - 49. DOI: 10.1007I s12639-014-0571-y

Junhul, D., Teng, Y.M., Guangen, M. (2015): The prevalence of common intestinal parasites in domestic pigs in Shaanxi province of China. Int. J. Food Sci. Microbiol., 3: 104 - 108

Kabululu, M.L., Ngowi, H.A., Kimera, S.I., Lekule, F.P., Kimbi, E.C., JOHANSEN, M.V. (2015): Risk factors for prevalence of pig parasitoses in Mbeya Region, Tanzania. Vet. Parasitol., 212: 460 - 464. DOI: 10.1016/j.vetpar.2015.08.006

KagiRA, J.M., KanYARI, P.W.N., Maingl, N., Githigia, S.M., NG'Ang'A, J.C., KARUGA, J.W. (2010): Characteristics of the smallholder freerange pig production system in western Kenya. Trop. Anim. Health Prod., 42: 865 - 873. DOI: 10.1007/s11250-009-9500-y

KaUR, M., SINGH, B.B., Sharma, R., GILL, J.P.S. (2017): Prevalence of gastro intestinal parasites in pigs in Punjab, India. J. Parasit. Dis., 41: 483 - 486. DOI: 10.1007/s12639-016-0833-y
Khan, M.N., Tauseef-Ur-Rehman, Sajd, M.S., Abbas, R.Z., Zaman, M.A., SIKANDAR, A.,(2013): Determinants influencing prevalence of coccidiosis in Pakistani buffaloes. Pakistan Vet. J., 33: $287-290$ KNeCHT, D., JankowsKa, A., Zaleśny, G.(2012): The impact of gastrointestinal parasites infection on slaughter efficiency in pigs. Vet. Parasitol., 184(2 - 4): 291 - 297. DOI: 10.1016/j.vetpar.2011.09.006

Krishnamurthy, C.M., Ananda, K.J., Adeppa, J., Satheesha, M.G. (2016): Studies on gastrointestinal parasites of pigs in Shimoga region of Karnataka. J. Parasit. Dis., 40: 885 - 889. DOI: 10.1007/ s12639-014-0598-0

Kouam, M.K., Ngueguim, F.D., Kantzoura, V. (2018):Internal Parasites of Pigs and Worm Control Practices in Bamboutos, Western Highlands of Cameroon. J. Parasitol. Res., Article ID 8242486, 10 pages. DOI: 10.1155/2018/8242486

Laha, R., Das, M., Goswami, A., Sallo, A., Sharma, B.K., Gangmel, D., Puil, L.H., Patra, M.K., Das, K., Sharma, A.,Ngullie, E. (2014):Prevalence of gastrointestinal parasitic infections in pigs of North Eastern Region of India. Ind. J. Hill Farming, 27: 59-63

Lal, M., Zhou, R.Q., Huang, H.C., Hu, S.J.(2011): Prevalence and risk factors associated with intestinal parasites in pigs in Chongqing, China. Res. Vet. Sci.,91: 121 - 124. DOI: 10.1016/j. rvsc.2011.01.025

LiPendele, C.P., LeKule, F.P., Mushi, D.E., Ngowi, H., KimBi, E.C., MeJer, H. (2015): Productivity and parasitic infections of pigs kept under different management systems by smallholder farmers in Mbeya and Mbozi districts, Tanzania. Trop. Anim. Health Prod., 47: 1121 - 1230. DOI: 10.1007/s11250-015-0836-1

MAFF (1986): Manual of Veterinary Parasitological Laboratory Techniques, Her Majesty Stationery Office, HMSO, London.

Marufu, M.C., Chanayima, P., Chimonyo, M., Bhebhe, E. (2008): Prevalence of gastrointestinal nematodes in Mukota pigs in a communal area of Zimbabwe. African. J. Agri. Res., 3: 91 - 95

Muraleedharan K. (2005): Prevalence of gastrointestinal parasites of livestock in a central dry zone of Karnataka. J.Vet. Parasitol., 19: $31-33$

Navarro-Gonzalez, N., Fernández-Llario, P., Pérez-Martín, J.E., MentaBerRe, G., López-Martín,J.M., Lavin, S. (2013): Supplemental feeding drives endoparasite infection in wild boar in Western Spain. Vet. Parasitol., 196: 114 - 123. DOI: 10.1016/j.vetpar.2013.02.019 Nissen, S., Poulsen, I. H., Nejsum, P., Olsen, A., Roepstorff, A., RuBAIRE-AKIIKI, C. (2011): Prevalence of gastrointestinal nematodes in growing pigs in Kabale District in Uganda. Trop. Anim. Health Prod., 43: 567 - 572. DOI: 10.1007/s11250-010-9732-x

Obonyo, F.O., Maingi, N., GithiGIA, S.M., NG'AnG'A, C.J. (2013): Farming practices and risk factors for transmission of helminths of free range pigs in Homabay District, Kenya. Livest Res Rural Dev, 25: 36

Okorafor, U.P., Unigwe, C.R., OKorafor, J.C., Isegbe, E.I., Ogbu, U.M., ATOYEBI, T.J. (2014): A Survey of gastrointestinal parasites of pigs that arrived for slaughter at Bodija Abattoir, Ibadan, Oyo State. Int. J. Pure Appl. Sci. Technol., 20: 53 - 57 
Ózsvárl, L. (2018): Production impact of parasitisms and coccidiosis in swine. J. Dairy. Vet. Anim. Res.,7(5): 217 - 222. DOI: 10.15406/jdvar.2018.07.00214

Patra, G., Riyadh, Al-Abodi H., Sahara, A., Ghosh, S., Borthakur, S.K., Polley, S., Behera, P. \& DekA, A. (2019): Prevalence of parasitic fauna of pigs in North-Eastern region of India. Biol Rhythm Res, DOI: 10.1080/09291016.2019.1573460

Permin, A., Yelifari, L., Bloch, P., Steenhard, N., Hansen, N.P., Nansen, P. (1999): Parasites in cross-bred pigs in the Upper East region of Ghana. Vet. Parasitol., 87: 63 - 71

RobeRTs, F.H.S., O'sulLivan, P.J. (1950): Methods for egg counts and larval cultures for strongyles infesting the gastro-intestinal tract of cattle. Aust. J. Agric. Res.,1:99 - 102

Roeber, F., Jex, A.R., Gasser, R.B. (2013): Impact of gastrointestinal parasitic nematodes of sheep, and the role of advanced molecular tools for exploring epidemiology and drug resistance - an Australian perspective. Parasit. Vectors., 6: 153. DOI: 10.1186/1756-3305-6-153

RoEPSTORFF, A., JoRSAL, S.E. (1989): Prevalence of helminth infections in swine in Denmark. Vet. Parasitol., 33: 231 - 239

Roepstorff, A., Nilsson, O., Oksanen, A., Guerde, B., Richter, S.H., ÖRTENBERG, E. (1998): Intestinal parasites in swine in the Nordic countries: Prevalence and geographical distribution. Vet. Parasitol.,76: $305-319$

Roesel, K., Dohoo, I., Baumann, M., Dione, M., Grace, D., Clausen, P.H. (2017): Prevalence and risk factors for gastrointestinal parasites in small-scale pig enterprises in Central and Eastern Uganda. Parasitol. Res. 116: 335 - 345. DOI: 10.1007/s00436-016-5296-7 Salvador, R.T., Abalos, R.P., Ruba, A.M., Mingala, C.N. (2014): A comparison of FLOTAC and CFF techniques in detecting gastrointestinal parasites in water buffaloes (Bubalus bubalis). Ann. Parasitol., 60(2): 119 - 125

Singh, A.K., Das, G., Nath, S., Kumar, S., Naresh, R. And Agrawal, V. (2017): Prevalence of gastrointestinal parasitic infections in pig in and around Jabalpur, Madhya Pradesh, India. Indian Vet. J., 94: $17-19$
SoulsBY, E.J.L. (1982): Helminths, Arthropod and Protozoa of Domesticated Animals, 7th edn, Bailliere Tindal, London, pp. 136 $346,593-614,763-778$

SuzUKI, R., SHIMODAIRA, H.(2006): Pvclust: an R package for assessing the uncertainty in hierarchical clustering. Bioinformatics., 22(12):1540 - 42. DOI: 10.1093/bioinformatics/btl117

Tamboura, H.H., Banga-Mboko, H., Maes, D., Youssao, I., Traore, A., BAYALA, B. (2006): Prevalence of common gastrointestinal nematode parasites in scavenging pigs of different ages and sexes in eastern centre province, Burkina Faso. Onderstepoort J. Vet. Res.,73: $53-60$

Timari, K.P., Chikweto, A., Belot, G., Vanpee, G., Deallie, C., StratTON, G. (2009): Prevalence of intestinal parasites in pigs in Grenada, West Indies. West Indian. Vet. J., 9: 22 - 27

ToIvo, J., ERIKA, M. (2003): Pig Endoparasites in Estonia. In Proceedings of International Scientific Conference Animals. Health. Food Hygiene.14th November, 2008. Jelgava, Latvia: Animal Health and Food Hygiene, pp. $54-58$

Tsunda, B., IJASINI, S.B., JamaL, G.Y. (2013): Porcine Coccidiosis: Prevalence study in Ganye Southeasthern Admawa State, Nigeria. IOSR J Agric Vet Sci, 6: $44-46$

VARGHeSE, T. (1986): Porcine coccidia in Papua New Guinea. Vet. Parasitol., 21: 11 - 20. DOI: 10.1016/0304-4017(86)90138-X

WEKA, R.P., IKEH, E.I. (2009): Seroprevalence of cysticercosis and intestinal parasitism in pigs in Jos Metropolis. J Anim Vet Adv, 8: 883 - 87. DOI: javaa.2009.883.887

YadAV, A.K., TANDON, V. (1989): Nematode parasite infections of domestic pigs in a sub-tropical and high-rainfall area of India. Vet. Parasitol., 31: 133 - 139

Yui, T., Shibahara, T., Kon, M., Yamamoto, N., Kameda, M., Taniyama, H. (2014): Epidemiological studies on intestinal protozoa in pigs in saitama, Japan. Jpn. Agric. Res. Q., 48: 87 - 93. DOI: 10.6090/ jarq. 48.87 